\title{
HuMANITIES
}

\section{Mentorship for Women in Medicine}

\author{
Constance LeBlanc MD CCFP(EM) FCFP MAEd', Carla Ross PhD² \\ ${ }^{1}$ Professor of Emergency Medicine and Associate Dean for CME, Faculty of Medicine, Dalhousie University \\ ${ }^{2}$ Director of Research Development, Dalhousie University
}

\begin{abstract}
This essay includes a brief history of women in medicine and the challenges they have encountered in developing mentoring relationships. We have provided some observations from peers and of our own, on women physicians and women working in medicine at different stages in their lives and in their careers, and the need for vigilance and assertiveness. Family responsibilities often interfere with career goals and mentors can play a key role in strategic career management at these times. The importance of strong role models and mentors for all professionals is increasingly documented. Some tips are provided to help reduce the challenges encountered in building strong relationships with suitable mentors.
\end{abstract}

In taking the Hippocratic Oath we vow to, "respect the hard-won scientific gains of those physicians in whose steps I walk, and gladly share such knowledge as is mine with those who are to follow." In order to fulfill this obligation, strong mentorship and guidance are essential.

In 1868, Dr. Emily Howard Stowe became the first Canadian woman to practice medicine in Canada. She studied medicine in the United States; no Canadian institution admitted women to medical school at that time. ${ }^{2}$ Since then, much progress has been made; those were the days when female students were excused from genital examinations. Biases still remain; however, as evidenced by the polarization of women across medical specialties towards specialties involving children (pediatrics and obstetrics and gynecology) and those that are more nurturing in nature (family medicine, psychiatry). ${ }^{3}$ Interestingly, these tend to be the least well remunerated areas in medical practice, although we do see female physicians in all specialties. ${ }^{4}$ As a word of caution, it should be noted that more studies are required as these facts have not been formally connected in Canada.

Women entering medicine often don't realize the role of shared anecdotes or the importance of relationships as they succumb to the pressure to rush home to their families at the end of their work day. This may be the result of several hundred years of history during which women worked in their homes, raising children and tending to family needs. Regardless of the cause, the effect is that we miss opportunities for discussion and valuable informal mentoring that occurs during social interactions, not to mention the opportunities for more formal mentoring from colleagues working in areas of common interest.

Women, including physicians, "continue to assume greater responsibility for family commitments in addition to their professional workload compounding their stress."3 Respite from excessive workload, academic endeavours, business travel, clinical shifts or other opportunities may be desirable, required or planned by women to allow time to attend to other obligations, but attention must be paid to ensure that this is indeed informed and intentional. Female physicians may be "protected" from opportunities, "for their family's sake" through opportunism by colleagues. This may be an unconscious decision reflecting their personal values, or a result of careerism. Women working in collaboration with physicians may suffer some of the same biases as mentorship and caring for others is part of our culture.

Re-entry mentoring is an important and typically neglected aspect of mentoring. Following a hiatus in activity or even a period of decreased activity, access to a mentor would mitigate the implication of a lack of dedication to one's career or sense of stigma, in addition to promoting renewed momentum and confidence at work. $^{5}$

Forming mentoring relationships is more challenging for women in medicine and in other disciplines where mentors and leaders are predominantly male. ${ }^{6}$ Perhaps, it is the fear that socializing may be misinterpreted by the other party as something more than the transference 
of knowledge and values. This is not totally unfounded. Female physicians in training continue to report higher rates of intimidation and sexual harassment than do their male counterparts, which makes relationships delicate to manage. ${ }^{3}$ The evolving gender distribution in medicine coupled with more relaxed social norms has provided more flexibility in this regard.

It is imperative for junior physicians to identify with their seniors, and not fear asking for help and forming social relationships at work. Role models need not be women, but these individuals must be truly interested and willing to provide guidance and direction, and be skilled in the art of delivery of honest and effective feedback. It is well documented that male physicians rarely start their first job without a mentor, whereas women must endeavour to seek out these opportunities. $^{7,8}$

Many professionals have several mentors throughout their careers. Early career direction and academic development may be a forte of one mentor, while managing the stress of young children or the sleepless nights of parenting teens that of another. You may need direction in one area or feel that the personal aspects of your life should remain private. This will depend on your personality and on your relationship with your mentor. When compared to mentored counterparts, women who feel they are able to direct their own careers singlehandedly will likely suffer a significant career lag by missing out on many learning opportunities coupled with a strong sense of direction. Having someone you can trust and respect, someone genuinely on your side, a person who will foster your growth, even over their own, and rejoice in your achievements cannot be overestimated.

The value of mentorship is now broadly recognized. Formal mentorship assignments have been implemented for new faculty at many medical schools including here at Dalhousie Medical School. Taken from bits and pieces of mentoring programs from across the country, we have established a program that is unique to our needs and consumers. The primary goal is simple; we want our faculty to excel - in research, in teaching and in clinical care. All faculty members deserve a rewarding academic career. New faculty members are expected to deal with varied and high demands ranging from teaching, research, clinical care and community service while accommodating a personal shift in life

\section{iupper trail}

\section{Our innovative curriculum includes:}

- Case-based learning

- Professional Competencies unit

- Rural Week

- Health Mentors

- Early clinical exposure

This is our pathway to graduating MDs who are: skilled clinicians, professionals, lifelong learners and community contributors.

\section{Our vision is to have the best undergraduate medical education program in North America by:}

- Attracting the best students from all sectors of our community.

- Having teachers who love to teach.

- Conducting research in medical education which critically examines what we are doing and continually improves our programs.

- A robust postgraduate medical education with 55 residency programs.

- An innovative continuing medical education program -- the 40-year segment of your medical education.

All delivered in a collegial environment.
PROFESSIONAL

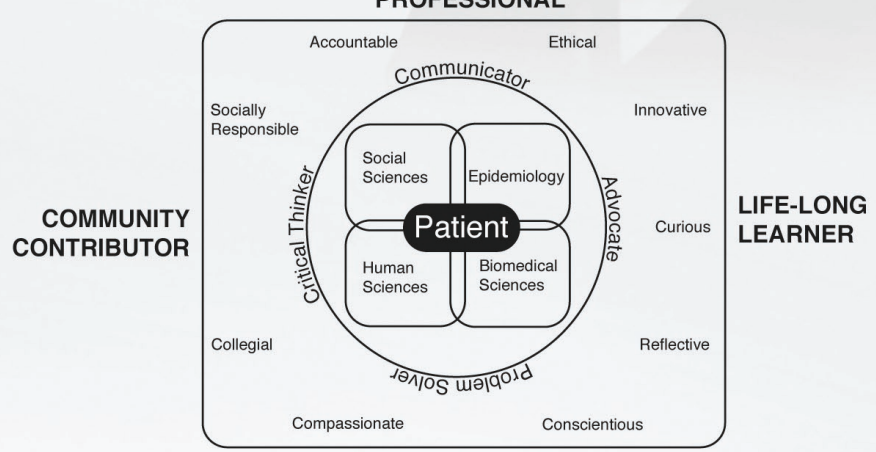

SKILLED CLINICIAN

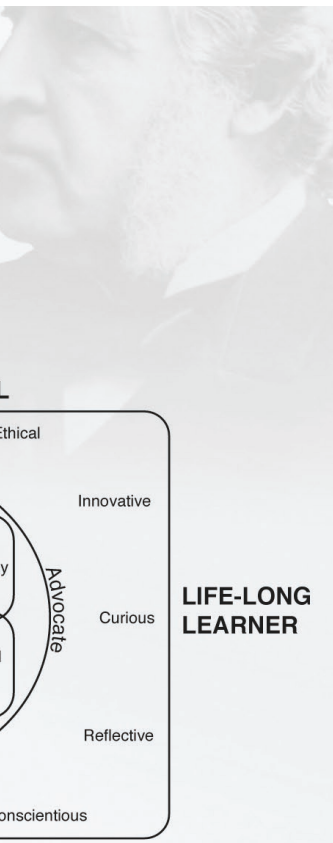

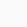


style. Finding this balance can be challenging for senior faculty, let alone new faculty just starting their career. A mentoring program represents one way to assist new faculty members to make wise and strategic decisions concerning the best way to launch and maintain an academic career and enhance the professional skills required for success. Adopting a formal/informal style (formal in that there is a requirement to meet and an evaluation process and informal in that it is not prescriptive of the frequency or nature of the meetings), junior faculty are "matched" with a senior mentor. It is left to the mentee/mentor to determine on what aspects they choose to focus. Opportunities to socialize and network are also a component of Dalhousie Medical School's mentoring program. Still in its infancy, there is opportunity to further customize for the wants and needs of our faculty.

The National Institute of Health has a re-entry after childrearing mentorship program to prevent career lag in this group of scientists. ${ }^{6}$ Effective strategies for finding mentors include staying late on occasion to share common interest such as research, seeking help when needed and working hard when the opportunity arises. None of these will ever trump enthusiasm, demonstrated ability or most importantly seeking feedback. Most senior clinicians faced challenges when they entered medicine and will provide invaluable advice to their juniors based on experience. They may, however, not wish to impose despite their willingness to share their perspectives and expertise if invited. It is paramount that women in medicine adopt strategies and tactics that will serve to develop these relationships and provide exposure to those with experience, such as suggesting collaborative work and asking for advice.

We need mentors, whether we recognize it or not. These valuable senior leaders contribute to enhanced productivity, education and well-being of their mentees throughout their careers. Time spent in mentormentee relationships is a contribution to ourselves and to society we can ill afford to ignore.

\section{Personal Reflections from the Authors:}

\section{Constance LeBlanc}

My mentor is a man. Gender has not impeded his ability to provide me with strong, insightful direction and career advice. He has provided me with clinical and academic tough love and direction, and I have reaped the rewards of his thoughtful counsel. I am

indebted to him for sharing his wisdom and my repayment to him has taken the form of furthering his

legacy through mentoring others, many of whom are women.

\section{Carla Ross}

My mentor was a colleague whom I admired and respected. She held a senior leadership position in research administration and was instrumental in establishing a new research office in a health centre. I often sought her advice on my career goals. She was my sounding board and the person to whom I vented most. My mentor retired last year and I have to admit, I have been feeling a bit lost. But all good things must come to an end and, while that relationship has ended, my search for a replacement has not.

\section{References}

1. Hippocrates. "Hippocratic oath". 5th century BCE.

2. Monroe DE. "Famous canadian women: famous firsts" Famous Canadian Women. 2004. http://www.famouscanadianwomen. com/famous\%20firsts/medical\%20professionals.htm Accessed: September 6, 2011.

3. Doig A. "Presentation to the standing committee on the status of women". April 19, 2010 http://www.cma.ca/advocacy/committeeon-the-status-of-women Accessed: August 25, 2011.

4. Lo Sasso AT, Richards MR, Chou C-F, Gerber SE. The $\$ 16,819$ pay gap for newly trained physicians: the unexplained trend of men earning more than women. Health Affairs; 30(2):193-201.

5. Office of Research on Women's Health. "ORWH-supported career development and mentoring programs" NIH Office of Research on Women's Health (ORWH) Resources. March 20, 2009 http:// womeninscience.nih.gov/resources/nih.asp Accessed: August 25, 2011.

6. Goudreau J. "Men benefit from mentors more than women". Forbes Magazine online. December 14, 2010. http://www. forbes.com/sites/jennagoudreau/2010/12/14/men-benefit-frommentors-more-than-women-money-salary-raise-wage-gappromotion/ Accessed: October 7, 2011

7. Noe RA, 1988. Women and Mentoring: A review and research agenda. Academy of Management Review, 13(1): 65-78.

8. Maack MN and Passet J. Aspirations and mentoring in an academic environment: women faculty in library and information science. 1994. Praeger Publishers, Westport, CT. 